\title{
Reduced cholesterol metastability of hepatic bile and its further decline in gall bladder bile in patients with cholesterol gall stones
}

\author{
K Nakano, K Chijiiwa
}

\begin{abstract}
The reduced metastability of biliary cholesterol in the gall bladder bile of patients with cholesterol gall stones has been well shown. The purpose of this study was to examine the hypothesis that such a difference in metastability already exists in hepatic bile. Paired hepatic and gall bladder bile samples were collected from 10 patients with cholesterol gall stones and six patients without gall stones. Cholesterol nucleation time, biliary lipid concentration, vesicular cholesterol distribution, and biliary protein concentration were measured and compared. The nucleation time in the hepatic bile of patients with cholesterol gall stones was significantly shorter than the gall stone free patients $(8 \cdot 2(7 \cdot 2) v 15.7(5.8)$ days, $p<0.05)$, and was associated with a greater concentration of biliary lipid despite the lack of a difference in the cholesterol saturation index (CSI) and total protein concentration. During the storage of bile in the gall bladder, the nucleation time became quicker in the patients with cholesterol gall stone (2.9 $(1.7)$ days) while it was similar in the gall stone free patients $(17.3(5.7)$ days) compared with that of the corresponding hepatic bile. These differences were associated with a higher CSI $(1.44(0.33) v 1.13(0.14), \mathrm{p}<0.05)$ and a greater vesicular cholesterol distribution $(19.7$ (11.9) $v$ $4.4(1.4) \%, p<0.01)$ in the patients with cholesterol gall stones than the gall stone free patients. The concentrations of total lipid and protein in gall bladder bile were not significantly different between the two groups. In conclusion, patients with cholesterol gall stones produce less metastable hepatic bile by the evidence of shorter nucleation time. During the storage of the bile in the gall bladder, the metastability is reduced further only in the cholesterol gall stone patients but not in the gall stone free patients.

(Gut 1993; 34: 702-707)
\end{abstract}

Biliary supersaturation with cholesterol is a prerequisite for cholesterol gall stone formation.

Department of Surgery I, Kyushu University Faculty of Medicine, Fukuoka 812, Japan K Nakano

K Chijiiwa

Correspondence to:

Dr K Chijiiwa, Department of Surgery I, Kyushu University Faculty of Medicine, 3-1-1,

Maidashi, Higashi-lu,

Fukuoka 812, Japan.

Accepted for publication

28 September 1992

Patients without cholesterol gall stones (gall stone free and pigment gall stone patients), however, often have bile supersaturated with cholesterol. ${ }^{1-3}$ These findings suggest that factors, in addition to biliary cholesterol saturation, are responsible for the formation of cholesterol gall stones. The stability of biliary cholesterol verified by the first appearance of cholesterol monohydrate crystals (nucleation time), rather than the cholesterol saturation index (CSI), is considered to be a better index for differentiating bile metastability. ${ }^{3}$ Cholesterol nucleation occurs from phospholipid cholesterol vesicles, ${ }^{46}$ the main carriers of cholesterol in addition to bile acid phospholipid cholesterol mixed micelles. Cholesterol nucleation is preceded by vesicle aggregation and fusion, ${ }^{78}$ and is believed to be an initial step in the formation of cholesterol gall stones.

Changes in biliary lipid composition such as high CSI, high bile acid/phospholipid molar ratio or low bile acid concentration accelerates cholesterol nucleation associated with a greater distribution of vesicular cholesterol.4-7910 Recently, a high total lipid concentration has been reported to reduce the metastability of bile. ${ }^{10-12}$ Furthermore, a high biliary concentration of total protein is reported to reduce bile metastability. ${ }^{12-14}$ The importance of pro $^{15-17}$ and anti-nucleating protein ${ }^{18} 19$ in bile has been shown. Thus, the metastability of biliary cholesterol is modulated by several factors such as biliary lipid composition, total lipid concentration, biliary protein, and the presence of stable/unstable vesicles.

Changes in the gall bladder, such as the increased absorption of water ${ }^{2021}$ and the hypersecretion of mucous glycoprotein ${ }^{2122}$ have also been shown to be responsible for cholesterol gall stone formation. There has been little investigation, however, as to how the metastability of hepatic bile changes in the gall bladder of patients with or without cholesterol gall stones. Furthermore, despite a possible difference in the cholesterol metastability of hepatic bile between the patients with cholesterol gall stones and control subjects, the nucleation time in hepatic bile has not been compared.

We hypothesised that the patients with cholesterol gall stones have less metastable hepatic bile which would become more lithogenic during the storage in the gall bladder. To examine the hypothesis, we verified the nucleation time, biliary lipid concentration, biliary protein concentration, and the distribution of vesicular cholesterol in paired hepatic and gall bladder bile from patients with or without cholesterol gall stones.

\section{Patients and methods}

\section{PATIENTS AND BILE SAMPLES}

Paired samples of hepatic and gall bladder bile were collected from 10 patients with cholesterol gall stones and six patients without gall stones at the time of surgery. The cholesterol gall stone patients consisted of eight women and two men, mean age $53 \cdot 8(16 \cdot 8)$. The gall stone free patients 
consisted of four women and two men, mean age $53 \cdot 5(17 \cdot 8)$. Four patients had gastric cancer and there was one case each of a solitary liver metastasis from thyroid cancer and a simple liver cyst. Cholecystectomy was carried out in patients with gastric cancer to dissect lymph nodes in porta hepatica and to prevent cholecystitis after gastrectomy. There were no significant differences in the sex and age distribution between the two groups. All patients had a normal ordinary food intake with mean per cent ideal body weight of $104 \cdot 8(16 \cdot 2) \%$. Their liver function tests (glutamic oxaloacetic transaminase, serum alkaline phosphatase, and serum bilirubin) were all within the normal range. Informed consent was obtained from all patients.

Gall bladder bile samples were collected after the ligation of the cystic duct by the complete sterile needle aspiration of the gall bladder to prevent the stratification of bile. ${ }^{23} \mathrm{~A}$ balloon catheter was cannulated into the common bile duct through the cystic duct and a sample of 2-3 ml of hepatic bile was collected through the hole proximal to the inflated balloon to prevent contamination by pancreatic and duodenal juice. Each patient had a functional gall bladder according to the evidence of a clearly visible gall bladder and its contractile response to egg yolk recorded on the drip infusion cholangiogram before operation, and by a total biliary lipid concentration greater than $50 \mathrm{~g} / \mathrm{l}^{23}$

The paired hepatic and gall bladder bile samples thus collected were immediately transferred to the laboratory in sterile brown test tubes kept at $37^{\circ} \mathrm{C}$. The samples were immediately ultracentrifuged at $100000 \mathrm{~g}$ for two hours at $37^{\circ} \mathrm{C}$ (Hitachi 55P-72, Tokyo, Japan). The separated isotropic cholesterol crystal free phase between the great density sediment of the bottom and the buoyant supernatant phase was collected with a sterile needle and syringe. The absence of cholesterol crystals was confirmed with polarised light microscopy (Nikon XTP-II, Tokyo, Japan). The isotropic bile samples were subsequently used to measure the nucleation time and the relative distribution of vesicular cholesterol. Part of the bile samples were frozen at $-20^{\circ} \mathrm{C}$ until chemical analysis.

\section{NUCLEATION TIME AND RELATIVE DISTRIBUTION} OF VESICULAR CHOLESTEROL

Nucleation time, defined as the first appearance time of cholesterol monohydrate crystals, was measured as described by Holan et $a l^{3}$ with certain modifications. ${ }^{24}$ Isotropic bile samples were immediately transferred into small sterile brown glass tubes, flushed with nitrogen, sealed, and placed in an incubator at $37^{\circ} \mathrm{C}$ without shaking throughout the study period. An aliquot was examined daily for the appearance of cholesterol monohydrate crystals with their typical rhomboidal notched and plated structures under the polarised microscope for 21 days of study. When cholesterol monohydrate crystals did not appear during the study period, the nucleation time was recorded as 21 days.

Separation of vesicles from micelles was performed by the gel filtration method using a $350 \times 10 \mathrm{~mm}$ column packed with Sephacryl
S-300 gel (Pharmacia LKB, Uppsala, Sweden) as reported..$^{25}$ Although the validity of this method has been confirmed by comparison with other methods, ${ }^{26}$ it is now considered to be conventional and artificial. ${ }^{27}$ For a nonperturbed separation, the correct intermicellar bile salt concentration and species should be determined in each bile sample. Therefore, the relative distribution of cholesterol in the vesicular phase was measured and compared.

\section{CHEMICAL ANALYSIS}

Bile acids and cholesterol were simultaneously quantified by gas liquid chromatography using nordeoxycholic acid as an internal standard as described by Chijiiwa and Nakayama. ${ }^{28}$ Phospholipids were verified by Bartlett's method. ${ }^{29}$ The cholesterol saturation index was calculated from the tables provided by Carey. ${ }^{30}$ Total protein concentration was measured by the fluorometric technique described by Yamazaki et al. ${ }^{31}$ Briefly, $1 \mathrm{ml}$ of $50-100$ fold diluted bile was added to $1 \mathrm{ml}$ of trichloroacetic acid solution (final concentration $10 \%$ ) and placed at $4^{\circ} \mathrm{C}$ for 30 minutes. The solution was centrifuged at $1700 \mathrm{~g}$ for 30 minutes at $4^{\circ} \mathrm{C}$. This procedure was repeated twice. After discarding the supernatant, the precipitate was washed with diethyl ether/ethanol $(3: 1 \mathrm{vol} / \mathrm{vol})$ and then centrifuged as above. The delipidation procedure was also repeated twice. The final pellet was dissolved in borate buffer ( $\mathrm{pH} \mathrm{9.0)}$ ) and incubated overnight at $4^{\circ} \mathrm{C} .0 .5 \mathrm{ml}$ of fluorescamine solution $(0.03 \%$ in acetone) (Sigma, St Louis, MO, USA) was added to $1.5 \mathrm{ml}$ of each sample. After 15 minutes, fluorescence was measured at an excitation wavelength of $390 \mathrm{~nm}$ and an emission wavelength of $480 \mathrm{~nm}$ by means of fluorescence spectrophotometry (RF-500, Shimadzu, Kyoto, Japan) using bovine serum albumin as the standard.

\section{STATISTICAL ANALYSIS}

Data are represented as mean (SD). Differences were tested by the Mann-Whitney $U$ test for unpaired data and the Wilcoxon signed rank test for paired data. The least square method was used in calculating the correlations. A probability value less than 0.05 was considered to be statistically significant.

\section{Results}

NUCLEATION TIME

Figure 1 shows that the nucleation time of hepatic bile in the patients with cholesterol gall stones $(8 \cdot 2(7 \cdot 2)$ days) was significantly shorter $(p<0.05)$ than that in the gall stone free patients (15.7 (5.8) days). A significantly shorter nucleation time $(2 \cdot 9(1.7)$ days) was also seen in gall bladder bile from the cholesterol gall stone patients compared with the gall stone free patients $(17 \cdot 3(5 \cdot 7)$ days $)(\mathrm{p}<0 \cdot 01)$. Interestingly, in the cholesterol gall stone patients, the nucleation time of gall bladder bile was significantly -shorter $(p<0.05)$ compared with the corresponding value of hepatic bile. Such an 


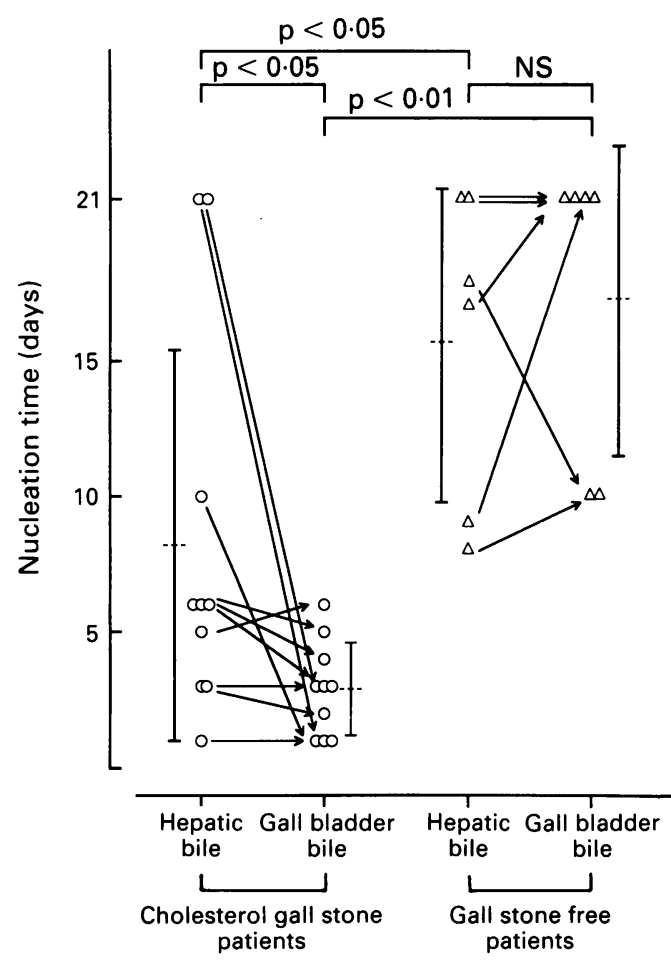

Figure 1: Nucleation time in paired samples of hepatic and gall bladder bile from patients with cholesterol gall stone $(\bigcirc)$ and gall stone free patients $(\triangle)$. Each arrow indicates the change in nucleation time from hepatic to gall bladder bile.

acceleration was absent in the gall stone free patients.

\section{BILIARY LIPID COMPOSITION AND TOTAL PROTEIN CONCENTRATION}

The Table shows the differences in biliary lipid composition and total protein concentration between the cholesterol gall stone patients and the gall stone free patients. The concentrations of total bile acids, cholesterol, and total lipid were significantly higher $(p<0.05)$ in the hepatic bile of the cholesterol gall stone patients than those of the gall stone free patients. The composition of individual bile acids was similar between the two groups. The concentration of phospholipids was also higher in the cholesterol gall stone patients but not to a significant degree. The molar per cent of cholesterol in hepatic bile was similar in the cholesterol gall stone patients and the gall stone free patients $(14 \cdot 1(4 \cdot 3) \% v$ $13.7(4 \cdot 7) \%)$. The CSI in hepatic bile of the cholesterol gall stone patients did not differ significantly from that of the gall stone free patients $(3.17(1.29)$ v $3.90(1 \cdot 82))$. Biliary protein concentration was similar between the two groups.

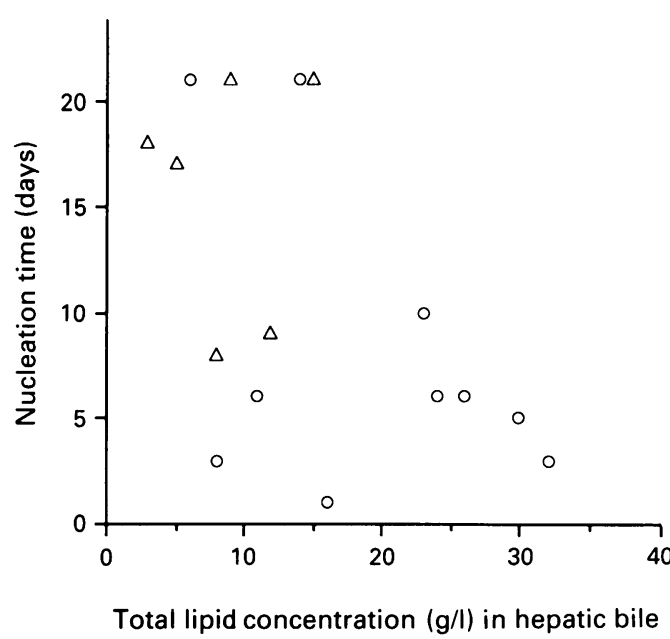

Figure 2: Relation between the nucleation time and total lipid concentration in hepatic bile. Correlation coefficients in patients with cholesterol gall stone $(\bigcirc)$, gall stone free patients $(\triangle)$, and the combined group were $-0.43(p=0.22), 0.02$ $(p=0.98)$, and $-0.53(p<0.05)$, respectively.

In gall bladder bile, no significant differences were seen between the two groups in the concentrations of each biliary lipid and total lipid. The composition of individual bile acids was similar between the groups. The molar per cent of cholesterol in gall bladder bile did not differ significantly between the groups $(9 \cdot 2(1 \cdot 9) v 8.6$ $(1 \cdot 8) \%)$. The CSI in gall bladder bile of the cholesterol gall stone patients, however, was significantly greater $(p<0.05)$ than that of the gall stone free patients. No significant difference in total protein concentration was seen in gall bladder bile between the cholesterol gall stone patients and the gall stone free patients.

\section{DIFFERENCE IN DISTRIBUTION OF VESICULAR}

CHOLESTEROL

The relative distribution of vesicular cholesterol in hepatic bile of the cholesterol gall stone patients was higher than that of the gall stone free patients, but not to a significant extent $(42 \cdot 3$ $(14.9) \%$ v $21.9(21.0) \%)$. In gall bladder bile, a significantly greater distribution of vesicular cholesterol was found in the cholesterol gall stone patients compared with the gall stone free patients (19.7 (11.9)\% v 4.4 (1.4)\%, p<0.01) (Table).

RELATION BETWEEN NUCLEATION TIME AND CSI, TOTAL LIPID CONCENTRATION, TOTAL PROTEIN CONCENTRATION, OR VESICULAR CHOLESTEROL DISTRIBUTION

In hepatic bile, the nucleation time was inversely

Biliary lipid composition, total protein concentration, and the distribution of vesicular cholesterol

\begin{tabular}{|c|c|c|c|c|c|c|c|}
\hline & $\begin{array}{l}\text { Total bile acids } \\
(m M)\end{array}$ & $\begin{array}{l}\text { Cholesterol } \\
(\mathrm{mM})\end{array}$ & $\begin{array}{l}\text { Phospholipids } \\
(m M)\end{array}$ & $\begin{array}{l}\text { Total lipid } \\
\text { concentration } \\
(\mathrm{g} / \mathrm{l})\end{array}$ & $\begin{array}{l}\text { Cholesterol } \\
\text { saturation } \\
\text { index }\end{array}$ & $\begin{array}{l}\text { Total protein } \\
\text { concentration } \\
(m g / m l)\end{array}$ & $\begin{array}{l}\text { Distribution of } \\
\text { vesicular cholesterol } \\
(\%)\end{array}$ \\
\hline $\begin{array}{l}\text { Hepatic bile } \\
\text { Gall stone patients }(\mathrm{n}=10) \\
\text { Gall stone free patients }(\mathrm{n}=6) \\
\text { Gall bladder bile }\end{array}$ & $\begin{array}{l}23 \cdot 8(12 \cdot 0)^{\star} \\
10 \cdot 3(6 \cdot 2)\end{array}$ & $\begin{array}{l}4 \cdot 7(2 \cdot 2)^{\star} \\
2 \cdot 0(1 \cdot 1)\end{array}$ & $\begin{array}{l}7 \cdot 1(4 \cdot 1) \\
3 \cdot 5(1 \cdot 8)\end{array}$ & $\begin{array}{l}19(9)^{\star} \\
9(4)\end{array}$ & $\begin{array}{l}3 \cdot 17(1 \cdot 29) \\
3.90(1.82)\end{array}$ & $\begin{array}{l}1 \cdot 0(0 \cdot 7) \\
1 \cdot 2(1 \cdot 1)\end{array}$ & $\begin{array}{l}42 \cdot 3(14 \cdot 9) \\
21 \cdot 9(21 \cdot 0)\end{array}$ \\
\hline $\begin{array}{l}\text { Gall stone patients }(n=10) \\
\text { Gall stone free patients }(n=6)\end{array}$ & $\begin{array}{l}134 \cdot 8(69 \cdot 0) \\
197 \cdot 7(83 \cdot 7)\end{array}$ & $\begin{array}{l}17 \cdot 2(9 \cdot 3) \\
24 \cdot 8(9 \cdot 7)\end{array}$ & $\begin{array}{l}37 \cdot 0(23 \cdot 5) \\
62 \cdot 7(23 \cdot 2)\end{array}$ & $\begin{array}{l}101(54) \\
155(56)\end{array}$ & $\begin{array}{l}1 \cdot 44(0 \cdot 33)^{\star} \\
1 \cdot 13(0 \cdot 14)\end{array}$ & $\begin{array}{l}2 \cdot 1(1 \cdot 4) \\
1 \cdot 9(1 \cdot 3)\end{array}$ & $\begin{array}{l}19 \cdot 7(11 \cdot 9)^{\star \star} \\
4 \cdot 4(1 \cdot 4)\end{array}$ \\
\hline
\end{tabular}

${ }^{\star} \mathrm{p}<0.05,{ }^{\star \star} \mathrm{p}<0.01$; significantly different from the gall stone-free patients. 

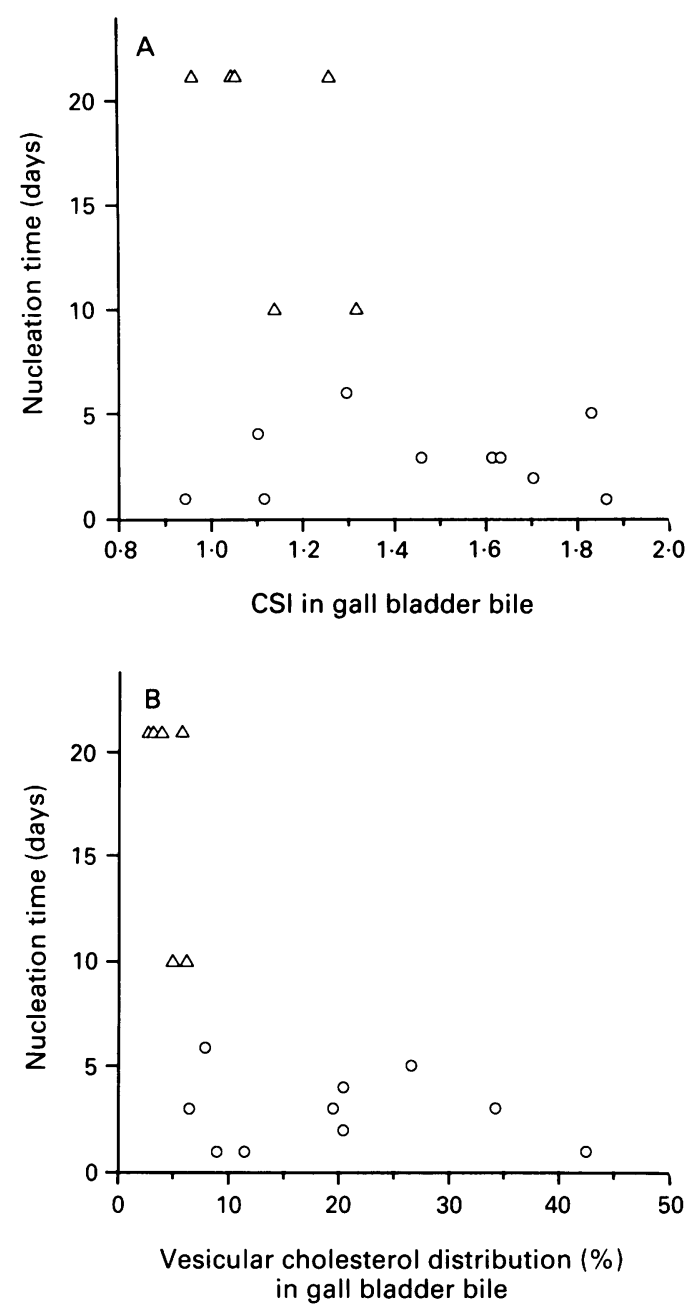

Figure 3: (A) Relation between the nucleation time and cholesterol saturation index (CSI) in gall bladder bile. Correlation coefficients in patients with cholesterol gall stone (O), gall stone free patients $(\triangle)$, and the combined group were $0.12(p=0.73),-0.60(p=0.21)$, and $-0.51(p<0.05)$, respectively. $(B)$ Relation between the nucleation time and vesicular cholesterol distribution in gall bladder bile.

Correlation coefficients in patients with cholesterol gall stone $(\bigcirc)$, gall stone free patients $(\triangle)$, and the combined group were $-0.02(p=0.95),-0.61(p=0.20)$, and $-0.61(p<0.05)$, respectively.

correlated with total lipid concentration when two groups were combined (Fig 2; $r=-0.53$, $\mathrm{p}<0.05$ ). Such a significant correlation, however, was absent in each bile sample taken from the cholesterol gall stone patients $(r=-0.43)$ or gall stone free patients $(r=0.02)$. No correlation was found between the nucleation time and CSI, total protein concentration or the distribution of vesicular cholesterol in hepatic bile.

In gall bladder bile, the nucleation time was inversely correlated significantly with the CSI $(\mathrm{r}=-0.51, \mathrm{p}<0.05)$ and with the distribution of vesicular cholesterol $(r=-0.61, p<0.05)$ when combined samples from the two groups were considered (Fig 3). When analysed separately in the cholesterol gall stone patients and gall stone free patients, there were no significant correlation of the nucleation time with the CSI $(r=0 \cdot 12$ and $r=-0 \cdot 60$, respectively, or with the distribution of vesicular cholesterol $(r=-0.02$ and $r=-0.61$, respectively). The nucleation time did not correlate with either total lipid concentration or total protein concentration.

\section{Discussion}

This is the first attempt to compare the biliary cholesterol metastability of paired hepatic and gall bladder bile between the patients with cholesterol gall stones and the gall stone free patients. The most important findings were: (1) hepatic bile, as well as gall bladder bile, is less metastable in the patients with cholesterol gall stones than the gall stone free patients; and (2) the metastability of bile is reduced further in the gall bladder only in the patients with cholesterol gall stones.

The nucleation time of gall bladder bile in cholesterol gall stone patients is quicker than that in gall stone free or pigment gall stone patients, ${ }^{324}{ }^{32}$ which was confirmed by this study. In addition, the nucleation time from more concentrated gall bladder bile has been reported to be quicker than that from hepatic bile in cholesterol gall stone patients. ${ }^{24}$ The reported nucleation times of hepatic bile from cholesterol gall stone patients were $9 \cdot 8(8 \cdot 6),{ }^{5} 7 \cdot 3(6 \cdot 5),{ }^{24}$ and $8 \cdot 8(7 \cdot 0)$ days ${ }^{33}$ comparable with our finding of $8.2(7 \cdot 2)$ days. There have been no studies reported, however, on the nucleation time of hepatic bile in gall stone free patients. In this study, hepatic bile of the cholesterol gall stone patients provided a significantly shorter nucleation time than that of the gall stone free patients. This indicates that cholesterol gall stone patients produce hepatic bile with a more reduced metastability of cholesterol compared with that of gall stone free patients.

Biliary lipid composition, the concentration of biliary protein, and the relative distribution of vesicular cholesterol were compared to examine the possible factors responsible for the difference in metastability of hepatic bile. Hepatic bile was supersaturated in a similar way in patients with cholesterol gall stones and gall stone free patients, which was consistent with the findings of Carey et $a l^{2}$ and Gallinger et $a l .^{14}$ Although the calculated CSI in very dilute bile (total lipid concentration $<10 \mathrm{~g} / \mathrm{l}$ ) possibly has an error as described by Carey, ${ }^{30}$ the molar per cent of cholesterol was also similar between the two groups. There was no correlation between the nucleation time and the CSI in hepatic bile. The total protein concentration in hepatic bile did not differ between the two groups as shown by Gallinger et $a l,,^{14}$ and was not connected with the nucleation time. The total lipid concentration was greater in the hepatic bile of patients with cholesterol gall stones than that in the gall stone free patients (Table). This may imply that the difference in total lipid concentration of diluted bile has a greater influence on the nucleation time compared with that of concentrated bile, as shown in model bile. ${ }^{710}$ In this study, the hepatic bile was possibly mixed with newly secreted bile, as time was required to collect the necessary volume. This explains the lower value of total lipid concentration in hepatic bile than that in retained bile of the common bile duct, but the value is within the range of values $(8-29 \mathrm{~g} / \mathrm{l})$ reported for hepatic bile collected by $T$ tube drainage. ${ }^{5692634}$ Previous studies $^{214}$ have shown that hepatic bile from cholesterol gall stone patients provides a greater total lipid concentration but not to a significant degree compared 
with controls. In this study, a significantly greater total lipid concentration was found in the hepatic bile of cholesterol gall stone patients. The reason for the greater total lipid concentration in cholesterol gall stone patients is not clear at present. A possible explanation is that the reduced bile flow as shown in cholesterol gall stone patients ${ }^{35}$ may enhance the absorption of water in the bile duct and may thus produce hepatic bile with a greater total lipid concentration. This could also be explained by the difference in biliary lipid secretion rate between the two groups. As a result, a greater biliary lipid concentration with a concomitant increase in the vesicular cholesterol distribution reduced the metastability of hepatic bile in the cholesterol gall stone patients. The nucleation time of hepatic bile in each group, however, was not significantly correlated with the total lipid concentration despite the presence of significant correlation in whole bile samples. The results suggest that the main factor differentiating the nucleation time between the two groups may be the difference in the activity of pro and antinucleating protein as both proteins coexist in hepatic bile. ${ }^{36}$ Whatever the mechanism is, the patients with cholesterol gall stones produce less metastable hepatic bile.

During the storage of such different metastable hepatic bile in the gall bladder, the metastability of bile was further reduced compared with the corresponding hepatic bile in the cholesterol gall stone patients, whereas such an effect was absent in the gall stone free patients (Fig 1). The factors differentiating metastability of gall bladder bile in two populations might be ascribed to the CSI and the distribution of vesicular cholesterol. This is partly supported by the evidence that the CSI and the distribution of vesicular cholesterol differed significantly between the two groups (Table) despite the lack of significant correlation between the nucleation time and these variables in each group (Fig 3). In contrast with hepatic bile, a significant difference in the total lipid concentration was not seen in gall bladder bile and the total lipid concentration did not correlate with the nucleation time of gall bladder bile. This may be because of the presence of gall stones, as gall bladder bile is more concentrated in the early stage of cholesterol gall stone formation but becomes diluted depending upon the severity of cholecystitis. ${ }^{122137}$

The total protein concentration did not differ between the two groups as shown by Yamazaki et al..$^{31} \mathrm{~A}$ role of the balance between the activity of pro and anti-nucleating protein has been also suggested to be a differentiating factor for the nucleation time. ${ }^{3638} \mathrm{~A}$ higher ratio of the concentration rate of protein to that of bile acids in gall bladder to hepatic bile was seen in the cholesterol gall stone patients than the gall stone free patients $(0.75(1.02) v 0 \cdot 15(0 \cdot 11), \mathrm{p}<0.05)$. This indirect evidence suggests a reduced absorption or increased secretion of protein, or both by the gall bladder leading to a change in the biliary protein fraction, as the gall bladder absorbs biliary protein selectively $\mathrm{y}^{39}$ and the increased CSI enhances the secretion of pronucleating protein mucin. ${ }^{22}$ The study ${ }^{40}$ that gall bladder bile from cholesterol gall stone patients had a higher concentration of mucin despite a similar total protein concentration compared with the controls supports this possibility. Thus, a higher CSI possibly associated with an increase in the pronucleating protein fraction could induce cholesterol rich vesicles, resulting in a further reduced metastability of gall bladder bile in the cholesterol gall stone patients.

In conclusion, cholesterol gall stone patients produce less metastable hepatic bile compared with gall stone free patients proved by the shorter nucleation time. During the storage in the gall bladder, biliary metastability becomes further reduced only in the cholesterol gall stone patients but not in the gall stone free patients. The gall bladder is the last place to produce bile that is likely to nucleate in the patients with cholesterol gall stones.

A part of this work was presented at the Annual Meeting of the American Gastroenterological Association held in San Francisco, May 1992.

1 Holzbach RT, Marsh M, Olszewski M, Holan KR Cholesterol solubility in bile: evidence that supersaturated bile is frequent in healthy man. $\mathcal{F}$ Clin Invest $1973 ; 52: 1467$ 79.

2 Carey MC, Small DM. The physical chemistry of cholesterol solubility in bile: relationship to gallstone formation and dissolution in man. $\mathcal{F}$ Clin Invest 1978; 61: 998-1026.

3 Holan KR, Holzbach RT, Hermann RE, Cooperman AM, Claffey WJ. Nucleation time: a key factor in the pathogenesis of cholesterol gallstone disease. Gastroenterology 1979; 77: 611-7.

4 Harvey PRC, Sömjen G, Lichtenberg MS, Petrunka CN, Gilat $T$, Strasberg SM. Nucleation of cholesterol from vesicles isolated from bile of patients with and without cholesterol isolated from bile of patients with and without cholest

5 Peled Y, Halpern Z, Baruch R, Goldman G, Gilat T. Cholesterol nucleation from its carriers in human bile. Hepatology 1988; 8: 914-8.

6 Peled Y, Halpern Z, Eitan B, Goldman G, Konikoff F, Gilat $T$. Biliary micellar cholesterol nucleates via the vesicular pathway. Biochim Biophys Acta 1989; 1003: 246-9.

7 Halpern Z, Dudley MA, Lynn MP, Nader JM, Breuer AC, Holzbach RT. Vesicle aggregation in model systems of supersaturated bile: relation to crystal nucleation and lipid composition of the vesicular phase. 7 Lipid Res 1986; 27 : 295-306.

8 Halpern Z, Dudley MA, Kibe A, Lynn MP, Breuer AC, Holzbach RT. Rapid vesicle formation and aggregation in abnormal human biles: a time-lapse video-enhanced contrast microscopy study. Gastroenterology 1986; 90: 875-85.

9 Pattinson NR, Chapman BA. Distribution of biliary cholesterol between mixed micelles and nonmicelles in relation to fasting and feeding in humans. Gastroenterology 1986; 91: 697-702.

10 Kibe A, Dudley MA, Halpern Z, Lynn MP, Breuer AC, Holzbach RT. Factors affecting cholesterol monohydrate crystal nucleation time in model systems of supersaturated bile. F Lipid Res 1985; 26: 1102-11.

11 van Erpecum KJ, van Berge Henegouwen GP, Stoelwinder B, Schmidt YMG, Willekens FLH. Bile concentration is a key factor for nucleation of cholesterol crystals and cholesterol saturation index in gallbladder bile of gallstone patients. Hepatology 1990; 11 : 1-6.

12 Strasberg SM, Toth JL, Gallinger S, Harvey PRC. High protein and total lipid concentration are associated with protein and total lipid concentration are associated with reduced metastability of bile in an early stage of cholestero
gallstone formation. Gastroenterology 1990; 98: 739-46.

13 Harvey RPC, Sömjen G, Gilat T, Gallinger S, Strasberg SM. Vesicular cholesterol in bile. Relationship to protein concentration and nucleation time. Biochim Biophys Acta 1988; 958: $10-8$.

14 Gallinger S, Harvey PRC, Petrunka CN, Ilson RG, Strasberg SM. Biliary proteins and the nucleation defect in cholestero cholelithiasis. Gastroenterology 1987; 92: 867-75.

15 Levy PF, Smith BF, LaMont JT. Human gallbladder mucin accelerates in vitro nucleation of cholesterol in artificial bile. Gastroenterology $1984 ; 87: 270-5$.

16 Gallinger S, Taylor RD, Harvey PRC, Petrunka CN, Strasberg SM. Effect of mucous glycoprotein on nucleation time of human bile. Gastroenterology 1985; 89: 648-58.

17 Harvey PRC, Upadhya GA, Strasberg SM. Immunoglobulins as nucleating proteins in the gallbladder bile of patients with as nucleating proteins in the gallbladder bile of patients with cholesterol gallstones. F Biol Chem 1991; 266: 13996-4003.

18 Holzbach RK, Kibe A, Thiel E, Howell JH, March M, Hermann RE. Biliary proteins: unique inhibitors of cholesterol crystal nucleation in human gallbladder bile. F Clin Invest 1984; 73: 34-45.

19 Kibe A, Holzbach RT, LaRusso NF, Mao SJT. Inhibition of cholesterol crystal formation by apolipoproteins in supersaturated model bile. Science 1984; 225: 514-6. 
20 Conter RL, Roslyn JJ, Porter-Fink V, DenBesten L. Gallbladder absorption increases during early cholesterol Gallbladder absorption increases during early ch.

21 Lee SP. Enhanced fluid transport across gallbladder mucosa in experimental cholelithiasis. Am $\mathcal{f}$ Physiol 1978; 234:

22 Lee SP, LaMont JT, Carey MC. Role of gallbladder mucus hypersecretion in the evolution of cholesterol gallstones: studies in the prairie dog. $\mathcal{F}$ Clin Invest 1981; 67: 1712-23.

23 Tera $\mathbf{H}$. Stratification of human gallbladder bile in vivo. Acto Chir Scand 1960; 256 (suppl): 1-85.

24 Gollish SH, Burnstein MJ, Ilson RG, Petrunka CN, Strasberg SM. Nucleation of cholesterol monohydrate crystals from hepatic and gall-bladder bile of patients with cholesterol gall stones. Gut 1983; 24: 836-44.

25 Hirota I, Chijiiwa K, Noshiro H, Nakayama F. Effect of chenodeoxycholate and ursodeoxycholate on nucleation time in human gallbladder bile. Gastroenterology 1992; 102: time in $h$.

26 Sömien GJ, Harvey PRC, Rosenberg R, Werbin N, Strasberg SM, Gilat T. Quantitation of phospholipid vesicles and their cholesterol content in human bile by quasi-elastic ligh scattering. Biochim Biophys Acta 1988; 963: 265-70.

27 Donovan JM, Carey MC. Separation and quantitation of cholesterol 'carriers' in bile. Hepatology 1990; 12: 94-105S.

28 Chijiiwa K, Nakayama F. Simultaneous microanalysis of bile acids and cholesterol in bile by glass capillary column gas chromatography. F Chromatogr 1988; 431: 17-25.

29 Bartlett GR. Phosphorus assay in column chromatography. 7 Biol Chem 1959; 234: 466-8.

30 Carey MC. Critical tables for calculating the cholesterol saturation of native bile. $\mathcal{F}$ Lipid Res 1978; 19: 945-55.

31 Yamazaki K, Powers SP, LaRusso NF. Biliary proteins: assessment of quantitative techniques and comparison in gallstone and nongallstone subjects. $\mathcal{F}$ Lipid Res 1988; 29: 1055-63.

32 Whiting MJ, Watts JM. Supersaturated bile from obese patients without gallstones supports cholesterol crystal
growth but not nucleation. Gastroenterology $1984 ; 86: 243-8$. 33 Burnstein MJ, Ilson RG, Petrunka CN, Taylor RD, Strasberg SM. Evidence for a potent nucleating factor in the gallbladder bile of patients with cholesterol gallstones. Gastroenterology 1983; 85: 801-7.

34 Ulloa N, Garrido J, Nervi F. Ultracentrifugal isolation of vesicular carriers of biliary cholesterol in native human and rat bile. Hepatology 1987; 7 : 235-44.

35 Shaffer EA, Small DM. Biliary lipid secretion in cholesterol gallstone disease: the effect of cholecystectomy and obesity. $\mathcal{f}$ Clin Invest 1977; 59: 828-40.

36 Groen AK, Stout JPJ, Drapers JAG, Hoek FJ, Grijm R, Tytgat GNJ. Cholesterol nucleation-influencing activity in T-tube bile. Hepatology 1988; 8: 347-52.

37 Nohrwold DL, Rose RC, Ward SP. Abnormalities in gallbladder morphology and function in patients with gallbladder morphology and function in patients with

38 Busch N, Matiuck N, Sahlin S, Pillay SP, Holzbach RT. Inhibition and promotion of cholesterol crystallization by protein fractions from normal human gallbladder bile. f Lipid Res 1991; 32: 695-702.

39 John WG, Mullock BM, Hinton RH. Proteins of guinea-pig bile: selective resorption in the gall bladder. Biosci Rep 1983; 3: 389-94.

40 Perdigoto R, Yamazaki K, LaRusso NF. Biliary glycoproteins: quantitative differences in subjects with and without gallstones [Abstract]. Hepatology 1988; 8: 1257. 